\title{
The environmental health catastrophe in Urmia Lake and asthma disease: a cohort study
}

\author{
Jafar Musapour ${ }^{1}$, Saeed Dastgiri², Mohammad Asghari Jafarabadi ${ }^{3}$, Parisa Ziasarabi², Zhila Khamnian ${ }^{4}$
}

\begin{abstract}
Background: Urmia Lake of Iran used to be the largest saltwater lake in the world. It has now disastrously shrunk to 10 percent of its previous size. This study aims to investigate the impact of this environmental catastrophe on the occurrence of asthma.

Methods: The whole population of ten districts in the area were investigated in this retrospective cohort study: "Exposed group" in the neighbouring areas of the lake, "Not exposed group 1" with medium distance $(65 \mathrm{~km})$ from the lake, and "Not exposed group 2" with more than $160 \mathrm{~km}$ from the lake. Clinical diagnosis of asthma was performed by the family physicians in the whole population.

Results: The occurrence risk of asthma in "Exposed group" was 1.85 times higher (CI95\%: 1.1- 3.0) than of "Not exposed group 1". The risk of disease, similarly, in "Exposed group" was 1.44 times more (C195\%: 0.9-2.3) when compared to "Not exposed group 2".

Conclusion: The country and provincial authorities should consider this hazardous climate change in the region seriously before it becomes a harmful event for millions of people living in the area.
\end{abstract}

Keywords: asthma, incidence, occurrence, Urmia Lake, Iran

\section{INTRODUCTION}

Urmia Lake is located in the southwest of Caspian Sea, northwest of Iran. It was, at its greatest extent, the largest saltwater lake in the world, with a surface area of approximately $5,200 \mathrm{~km} 2$, a length of $140 \mathrm{~km}$, a width of $55 \mathrm{~km}$, and a maximum depth of $16 \mathrm{~m}$. Over the last 1-2 decades, Urmia Lake has disastrously shrunk to 10 percent of its previous size due to damming of the rivers that used to flow into it, and the pumping of groundwater from the surrounding areas $(1,2)$. The dryness of this Lake has led to some harms and regional climate changes including salty dust exposure in inhabitants in the region. A similar environmental health disaster was previously reported from Aral Sea area bordering Kazakhstan and Uzbekistan in central Asia (3-5).

Over the past few decades, the prevalence of asthma has significantly increased in various places in the world with no clear reason. It is now estimated that more than 5 percent, on average, of the world population suffering of asthma. Some epidemiologists predict that by the year 2025, 100 million people will be added to the population of asthma patients worldwide (6-11).

Some studies show that prevalence of asthma in Iran is ranging from 3 to 35 percent in various places in the country (12-13).

This study aims to investigate the occurrence of asthma in the neighbouring areas of Urmia Lake to find whether the recent changes in this lake has had any effect on the pulmonary function (including asthma disease) of inhabitants in the area.

School of Public Health, Tabriz University of Medical Sciences, Tabriz, Iran

2 Tabriz Health Services Management Research Centre, Tabriz University of Medical Sciences, Tabriz, Iran.

3 Road Traffic Injury Research Centre, Tabriz University of Medical Sciences, Tabriz, Iran.

4 School of Medicine, Tabriz University of Medical Sciences, Tabriz, Iran

Received: 19 Feb 2019, Accepted: 20 May 2019

\section{Correspondence: Professor Saeed Dastgir}

School of Medicine, Tabriz University of Medical Sciences, Tabriz 5155668474, Iran.

E-mail: saeed.dastgiri@gmail.com

(C) 2019 by the authors; licensee Modestum Ltd., UK. This article is an open access article distributed under the terms and conditions of the Creative Commons Attribution License (http://creativecommons.org/licenses/by/4.0/). 


\section{Google Maps}

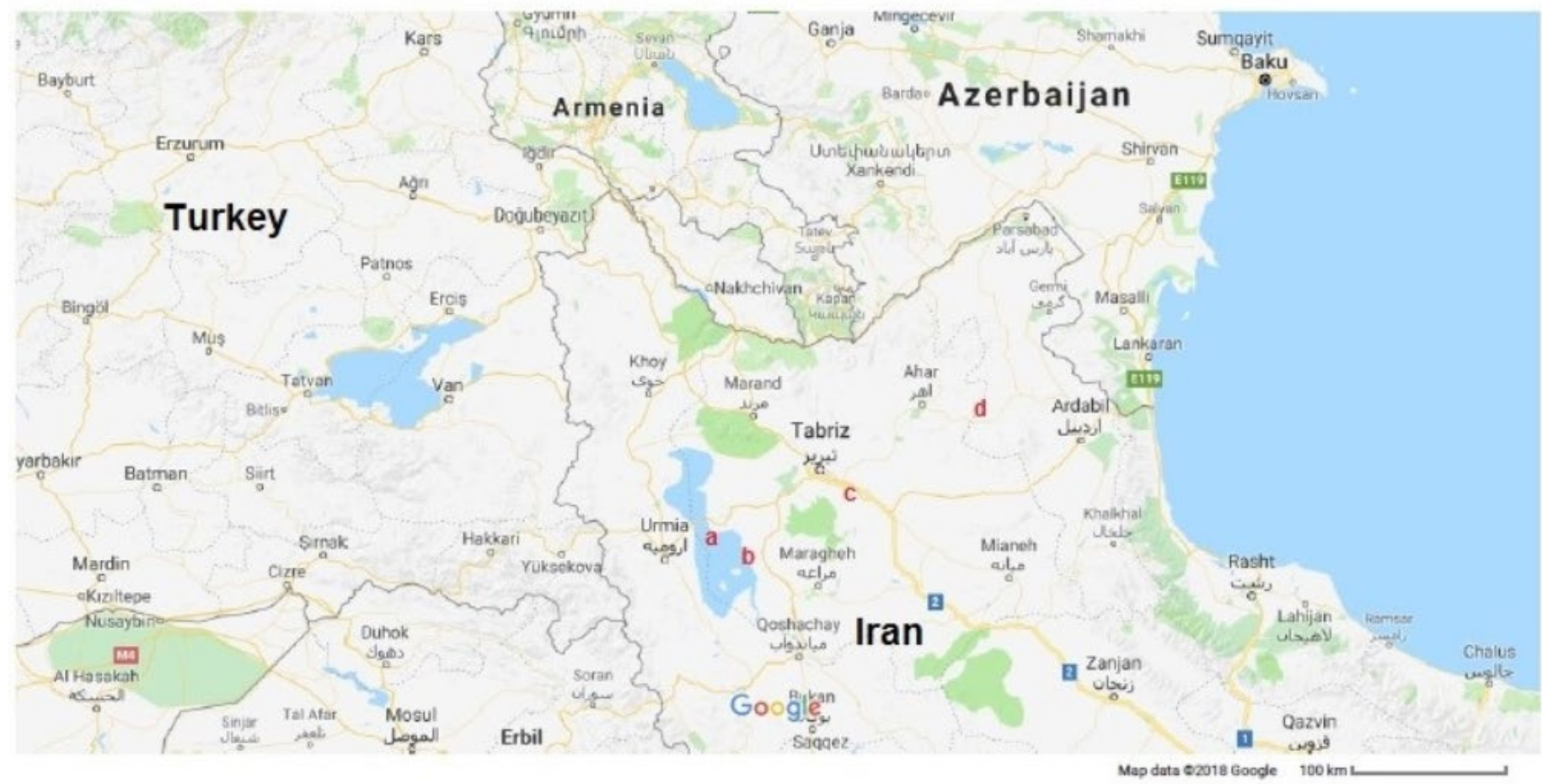

a: Urmia Lake $\quad$ b: Exposed group $\quad$ c: Not exposed group $1 \quad$ d: Not exposed group 2

Figure 1: Urmia Lake and the Study Areas in the Northwest of Iran

\section{METHODS}

In this retrospective cohort study, the whole population of ten districts in three areas in the northwest of Iran were investigated: five districts in the neighbouring areas of Urmia Lake (with less than $30 \mathrm{~km}$ distance from the lake) were selected as "Exposed group" (Sarai, Ghezel Dizaj, Kojabad, Mayan Olya and Mayan Sofla). The district of Dizaj Lilikhani that located in the southeast of the Tabriz city was selected as "Not exposed group 1" with medium distance (65 km) from the lake. Four other areas that were far from the Lake (more than $160 \mathrm{~km}$ ) were selected as "Not exposed group 2" including Reyhan, Kaqalaq, Kordlar and Naqarakoob districts. The geographical details of the study area are shown in Figure 1. The predominant direction of winds in the study population blows broadly from east to west areas. As indicated above, the "Exposed group" is in a very close distant from the lake while both "Not exposed" groups are located far away from the wind direction and the lake. It was then assumed that population in the "Exposed group" has the heaviest/strongest exposure to the salty dust induced by the changes in the lake over the past years compared to "Not exposed group 1,2".

We investigated a total population of 23787 individuals in three groups including: 17983 (male:9355, female:8628) in "Exposed group", 3107 (male:1600, female:1507) in "Not exposed group 1" and 2697 (male:1379, female:1318) in "Not exposed group 2". Clinical diagnosis of asthma was performed by the family physicians based on the official guidelines provided by the Ministry of Health and Medical Education. Information on the age, sex, occupation, smoking, family history of asthma, education, blood pressure, diabetes and duration of the disease were also collected. Those data were used (as confounding factors) in the analysis of data.

Incidence rate of asthma for a period of 10 years (2006 to 2016) was calculated in three levels of exposure in the study groups. We calculated the Relative Risk (RR) as the ratio of the probability of the occurrence of asthma in "Exposed group" to the probability of disease in "Not exposed" groups. Attributable Risk (AR) (similarly called Excess Risk and Risk Difference), was also calculated to show the attributable fraction of environmental pollution on the occurrence of asthma among "Exposed group". Confidence Intervals (C195\%) were calculated to estimate the statistical compatibility range of those epidemiological measures in the study population.

We obtained the ethics approval from the Ethics Committee of the Tabriz University of Medical Sciences for this study. Information was anonymised at source of data collection to keep personal information private. 
Table 1: The Incidence Rates (per 1000), Relative Risk and Attributable Risk (\%) of Asthma Disease (Urmia Lake Area, Iran, 2006-2016)

\begin{tabular}{ccccccc}
\hline & Incidence & Relative Risk & Attributable Risk\% & Relative Risk & Attributable Risk\% & Relative Risk Attributable Risk\% \\
\hline exposed & $10.12(8.6-11.5)$ & $1.85(1.1-3.0)$ & $45.94(9.6-82.3)$ & $1.44(0.9-2.3)$ & $30.39(-8.8-69.6)$ & $1.63(1.1-2.3)$ \\
\hline not exposed 2 & $5.47(2.9-8.1)$ & reference & reference & & & \\
\hline not exposed 3 & $7.04(3.9-10.2)$ & & & reference & reference & \\
\hline not exposed 2+3 & $6.20(4.2-8.2)$ & & & & reference & reference \\
\hline
\end{tabular}

Notes: numbers in Parentheses indicate 95 percent confidence intervals

Table 2: The Incidence Rates (per 1000), Relative Risk and Attributable Risk (\%) of Asthma Disease by Gender (Urmia Lake Area, Iran, 2006-2016)

\begin{tabular}{|c|c|c|c|c|c|c|c|}
\hline & Incidence & Relative Risk & Attributable Risk\% & Relative Risk & Attributable Risk\% & Relative Risk & Attributable Risk\% \\
\hline \multicolumn{8}{|l|}{ exposed } \\
\hline male & $8.01(6.2-9.8)$ & $1.83(0.9-3.9)$ & $45.43(-11.6-102.4)$ & $1.84(0.8-4.2)$ & $45.73(-15.3-106.8)$ & $1.84(1.0-3.3)$ & $45.56(2.3-88.9)$ \\
\hline female & $12.40(10.1-14.7)$ & $1.86(0.9-3.6)$ & $46.49(-0.6-93.6)$ & $1.25(0.7-2.2)$ & $20.47(-30.6-71.5)$ & $1.52(0.9-2.4)$ & $34.35(-1.9-70.6)$ \\
\hline \multicolumn{8}{|l|}{ not exposed 2} \\
\hline male & $4.37(1.1-7.6)$ & reference & reference & & & & \\
\hline female & $6.63(2.5-10.7)$ & reference & reference & & & & \\
\hline \multicolumn{8}{|l|}{ not exposed 3} \\
\hline male & $4.35(0.9-7.8)$ & & & reference & reference & & \\
\hline female & $9.86(4.5-15.2)$ & & & reference & reference & & \\
\hline \multicolumn{8}{|l|}{ not exposed 2+3 } \\
\hline male & $4.36(1.9-6.7)$ & & & & & reference & reference \\
\hline female & $8.14(4.8-11.6)$ & & & & & reference & reference \\
\hline
\end{tabular}

Notes: numbers in Parentheses indicate 95 percent confidence intervals

\section{FINDINGS}

A total of 218 cases of asthma patients were diagnosed by family doctors in the study population: 182 cases (male:75, female:107) in "Exposed group", 17 (male:7, female:10) in "Not exposed group 1", and 19 cases (male:6, female:13) in "Not exposed group 2" were identified/recruited for this study. The mean age of the patients was 53 years, and the average duration of illness was 5.7 years in asthmatic patients. The majority of the study subjects (53 percent) were housewives, and a very small proportion of them ( 0.5 percent) were employees of petrochemical and leather companies. Except age and sex, no confounder was found when compared three groups.

The annual incidence of disease was 10.12 (per 1000, Cl95\%: 8.6-11.5), 5.47 (per 1000, C195\%: 2.9-8.1) and 7.04 (per 1000, Cl95\%: 3.9-10.2) in "Exposed group", "Not exposed group 1" and "Not exposed group 2", respectively. The occurrence risk of asthma in "Exposed group" was 1.85 times higher (C195\%: 1.1- 3.0) than of "Not exposed group 1" (as reference group). The risk of disease, similarly, in "Exposed group" was 1.44 times more (Cl95\%: 0.9-2.3) when compared to "Not exposed group 2" (as reference group). It was found that the risk of asthma disease is 63 percent (CI95\%: 1.12.3) higher than both control groups (group1+group2). In the neighbouring population of the lake, the risk solely attributed to the exposure to this pollution for asthma disease was 38.7 percent (Cl95\%: 10.9-66.6) (Table 1).

Incidence rates, relative risk and attributable risk of the occurrence of asthma in three study cohorts (stratified by age and sex) are presented in Tables 2,3. Except for annual incidence of asthma, no major significant difference was found between males and females in the study population. The incidence rate of disease was always higher in females compared to males in all three exposure groups (Table 2 ).

As presented in Table 3, two age groups ( $<40$ vs. $>=40$ years) showed statistically significant difference in all three exposure levels in terms of annual incidence of asthma. However, the relative risk and attributable risk of the incidence of asthma were not significantly different when compared two age groups. 
Table 3: The Incidence Rates (per 1000), Relative Risk and Attributable Risk (\%) of Asthma Disease by Age Groups (Urmia Lake Area, Iran, 2006-2016)

\begin{tabular}{|c|c|c|c|c|c|c|c|}
\hline & Incidence & Relative Risk & Attributable Risk\% & Relative Risk & Attributable Risk\% & Relative Risk & Attributable Risk\% \\
\hline \multicolumn{8}{|l|}{ exposed } \\
\hline$<40$ & $3.60(2.6-4.6)$ & $1.57(0.6-3.9)$ & $36.32(-36.9-109.6)$ & _ & _ & $2.82(1.1-7.1)$ & 64.55 (9.9-119.2) \\
\hline$>=40$ & $33.47(27.8-39.1)$ & $2.54(1.4-4.6)$ & $60.56(23.9-97.1)$ & $1.49(0.9-2.4)$ & $33.18(-3.9-70.2)$ & $1.87(1.3-2.7)$ & $46.65(19.2-74.1)$ \\
\hline \multicolumn{8}{|l|}{ not exposed 2} \\
\hline$<40$ & $2.29(0.3-4.3)$ & reference & reference & & & & \\
\hline$>=40$ & $13.20(5.8-20.1)$ & reference & reference & & & & \\
\hline \multicolumn{8}{|l|}{ not exposed 3} \\
\hline$<40$ & 0 & & & reference & reference & & \\
\hline$>=40$ & $22.36(13.9-31.8)$ & & & reference & reference & & \\
\hline \multicolumn{8}{|l|}{ not exposed $2+3$} \\
\hline$<40$ & $1.28(0.1-2.4)$ & & & & & reference & reference \\
\hline$>=40$ & $17.86(11.2-23.9)$ & & & & & reference & reference \\
\hline
\end{tabular}

Notes: numbers in Parentheses indicate 95 percent confidence intervals

\section{DISCUSSION}

In this study, the occurrence risk of asthma in the neighbouring areas of the Urmia salty lake was investigated. We found that the risk of disease is significantly higher in the population in the districts around the lake compared to the population in control areas. We studied the association between the harms of salty dust pollution (induced by dryness of Urmia Lake in the region) and asthma disease in the inhabitants of regional population. This is the first study, in its kind, in this area of the northwest of Iran. As in any epidemiological investigation, there might happen an ecological fallacy in the interpretation of association found in this study. However, some supporting data has similarly been reported from Aral Sea region in central Asia (3-5). Additionally, the time course and pathophysiological pattern of relation between asthma and environmental pollution (including salt pollution etc) is based on a similar physiological response of the body immune response to a particular foreign substance. This response would normally result in the proliferation of the body immunological productions (i.e., immunoglobulins or antibodies etc) to the identified foreign substance. Genetic predisposition of individuals determines the severity of response to those substances. As a result, some individuals may show asthmatic reaction to salt substances exist in the area. Therefore, the dryness of this salty lake over the last two decades might seemingly have played a role in the increasing risk of asthma in the region.

As indicated, similar health and social problems have been investigated in the population in the Aral Sea area, central Asia (4). Bennion and colleagues investigated the respiratory symptoms and lung function in children aged 7-10 years living in 18 communities in the Aral Sea region. They found no relation between the prevalence of asthma and dust exposure in this population in the area (3).

A systematic review of the literature by Crighton and colleagues studied the impacts of the Aral Sea disaster on children health. They found that anemia, diarrheal diseases, and high body burdens of toxic contaminants were the most important health problems for children in the area. They did not find, however, clear association between dust exposure and respiratory function (5).

We conclude that the disastrous situation of Urmia Lake might have an impact on the risk of asthma in the regional population. However, as the limitation of this study, the role of other factors and the possibility of some types of bias (i.e., ecological fallacy in the interpretation of data, underlying diseases in the study subjects, the role of other pollutions in the regional environment etc) on the onset and recurrence of asthma symptoms cannot be ruled out. There is, therefore, need for further studies in order to investigate all aspects comprehensively in large scale groups in the area, and to identify the effect of the salty dusts induces by Urmia Lake more specifically. For the time being, however, the country and provincial authorities should consider this hazardous climate change in the region seriously before it becomes a harmful event for millions of people living in the area.

\section{ACKNOWLEDGEMENTS}

Setting up this study would not have been possible without the support of Tabriz University of Medical Sciences. We extend our gratitude to the people and family doctors in the region those who contributed and participated in this research. 


\section{Conflicts of Interest}

The authors have no conflicts of interest to declare.

\section{REFERENCES}

1. Statistics Administration Organization of Iran. Retrieved on 6 April 2018 from https://amar.org.ir

2. Online Encyclopaedia of Wikipedia. Retrieved on 16 March 2018 from https://en.wikipedia.org/wiki/Lake_Urmia

3. Bennion $P$, Hubbard R, O'hara S, Giggs G, Wegerdt J, Lewis $S$. The impact of airborne dust on respiratory health in children living in the Aral Sea region. Int J Epidemiol 2007;36(5):1103-10. https://doi.org/10.1093/ije/dym195 PMid:17911152

4. Small I, Van der Meer J, Upshur R. Acting on an environmental health disaster: the case of the Aral Sea. Environ Health Perspect 2001;109(6):547. https://doi.org/10.1289/ehp.01109547 PMid:11445505 PMCid:PMC1240333

5. Crighton EJ, Barwin L, Small I, Upshur R. What have we learned? A review of the literature on children's health and the environment in the Aral Sea area. Int J Public Health 2011;56(2):125-38. https://doi.org/10.1007/s00038010-0201-0 PMid:20976516 PMCid:PMC3066395

6. Wijesinghe $\mathrm{M}$, Weatherall $\mathrm{M}$, Perrin $\mathrm{K}$, Crane J, Beasley R. International trends in asthma mortality rates in the 5to 34-year age group: a call for closer surveillance. Chest 2009;135(4):1045-1049. https://doi.org/10.1378/chest.08-2082 PMid:19349400

7. Lai CK, Beasley R, Crane J, Foliaki S, Shah J, Weiland S. Global variation in the prevalence and severity of asthma symptoms: phase three of the International Study of Asthma and Allergies in Childhood (ISAAC). Thorax 2009;64(6):476-83. https://doi.org/10.1136/thx.2008.106609 PMid:19237391

8. Pearce N, Aitt-Khaled N, Beasley R, Mallol J, Keil U, Mitchell E, Robertson C. Worldwide trends in the prevalence of asthma symptoms: phase III of the International Study of Asthma and Allergies in Childhood (ISAAC). Thorax 2007;62(9):758-66. https://doi.org/10.1136/thx.2006.070169 PMid:17504817 PMCid:PMC2117323

9. Croisant S. Epidemiology of asthma: prevalence and burden of disease. Adv Exp Med Biol 2014;795:17-29. https://doi.org/10.1007/978-1-4614-8603-9_2 PMid:24162900

10. Lang DM. Severe asthma: epidemiology, burden of illness, and heterogeneity. Allergy Asthma Proc 2015;36(6):418-24. https://doi.org/10.2500/aap.2015.36.3908 PMid:26534747

11. Rabe KF, Adachi M, Lai CK, Soriano JB, Vermeire PA, Weiss KB, et al. Worldwide severity and control of asthma in children and adults: the global asthma insights and reality surveys. J Allergy Clin Immunol 2004;114(1):40-47. https://doi.org/10.1016/j.jaci.2004.04.042 PMid:15241342

12. Fazlollahi MR, Najmi $M$, Fallahnezhad $M$, Sabetkish $N$, Kazemnejad A, Bidad K, Shokouhi Shoormasti $R$, Mahloujirad M, Pourpak Z, Moin M. Pediatric Asthma Prevalence: The First National Population-based Survey in Iran. Clin Respir J 2018. https://doi.org/10.1111/crj.12975 PMid:30472812

13. Entezari A, Mehrabi $Y$, Varesvazirian $M$, Pourpak $Z$, Moin M. A systematic review of recent asthma symptom surveys in Iranian children. Chron Resp Dis 2009;6(2):109-14. https://doi.org/10.1177/1479972309103884 PMid:19411572

$\diamond \diamond \diamond \diamond \diamond \diamond \diamond$

http://www.ejgm.co.uk 